\title{
Doctoral program in optical science and engineering at the University of Alabama in Huntsville
}

\section{Stephen Kowel}

Stephen T. Kowel, "Doctoral program in optical science and engineering at the University of Alabama in Huntsville," Proc. SPIE 2525, 1995 International Conference on Education in Optics, (13 October 1995); doi: $10.1117 / 12.224030$

SPIE Event: SPIE's 1995 International Symposium on Optical Science, SPIE. Engineering, and Instrumentation, 1995, San Diego, CA, United States 


\title{
Doctoral program in optical science and engineering at
} The University of Alabama in Huntsville

\author{
Stephen T. Kowel \\ Department of Electrical and Computer Engineering \\ The University of Alabama in Huntsville \\ Huntsville, AL 35899 \\ Internet: kowel@ebs330.eb.uah.edu
}

\begin{abstract}
The Optical Science and Engineering Program at The University of Alabama in Huntsville was initiated in 1993 to provide advanced graduate education in fundamental and applied optics with a strong optoelectronics orientation. As a multidisciplinary program with the participation from science and engineering departments as well as the Center for Applied Optics, the OSE Program integrates all of the optics assets at UAH to offer outstanding research and instructional opportunities.
\end{abstract}

\section{INTRODUCTION}

In September, 1993, UAH initiated a new degree program, the Ph.D. in Optical Science and Engineering (OSE) with seven students. By the Fall, 1995, the program will have 15 students, and one degree granted in May, 1995. The OSE Program is quite unusual in that it is truly multidisciplinary in planning, administration, and in perspective. The goal of the program is to provide advanced education in both fundamental and applied optics, especially in optoelectronics. It is coordinated by a program committee composed of senior faculty from the major contributing departments; physics, electrical and computer engineering, mechanical and aerospace engineering, and chemistry. The program faculty of 18 is drawn from these departments as well as from the senior staff of the Center for Applied Optics (CAO). This broad array of faculty provides for specialized courses and research opportunities in areas as diverse as 3-D liquid crystal displays, optics design for dashboards, imaging polarimetry, photorefractive materials and applications, electro-optic polymer devices, fiber lasers, spatial light modulators, quantum optics, and optical computing.

\section{RATIONALE}

UAH has long had a commitment to optics as a major thrust area. Two undergraduate degrees are offered, a B.S. in Optical Science within the Physics Department, and a B.S.E. in Optical Engineering within the Electrical and Computer Engineering Department. In addition to developing strength in these and other academic units, the University created the Center For Applied Optics (CAO) as a research/development/technology transfer unit.

By 1991, optics-related activities were housed in the newly completed Optics Building, providing a common site for all students, faculty, and staff involved with optics. This facility provided a powerful incentive and opportunity to develop multidisciplinary research and instructional programs. A proposal for a Ph.D. degree in optical science and engineering was 
developed, with participation by other Alabama institutions. The University of Alabama at Birmingham (UAB), The University of Alabama (UA, Tuscaloosa), and the Alabama Agricultural and Mechanical University (AAMU) joined as cooperating institutions. Students can take courses and perform research at these institutions to fulfill UAH degree requirements.

An important consideration in proposing a new $\mathrm{PhD}$ program was the desirability of gaining national and international stature for doctoral programs at UAH. If we had continued to offer only $\mathrm{PhD}$ degrees with optics concentrations in the conventional disciplines, it would have been very difficult to gain prominence in such well developed, conventional fields with so many powerful, well-known programs. Thus, we believed that it would be much easier to gain visibility by developing a new degree specifically in optics, a field in which only a relatively few universities offer doctoral degrees. A program which integrated optical science and engineering with strong emphasis on optoelectronics would likely remain distinct, providing an opportunity to attract superior students who might choose other institutions if they had to select from among traditional degrees.

\section{THE FACULTY}

The current OSE faculty is drawn from UAH departmental faculty and research faculty who are primarily senior staff at the Center for Applied Optics. In the list below, the departmental affiliation is included (ECE stands for Electrical and Computer Engineering, $\mathrm{PH}$ stands for Physics, MAE for Mechanical and Aerospace Engineering, and CAO for Center for Applied Optics):

Abushagur, M. A. G. (ECE); optical signal processing, computing and metrology Ahmad, A. (CAO); opto-mechanical engineering, expert systems, rapid proto-typing Banerjee, P. P. (ECE); nonlinear wave phenomena, optical processing Chipman, R.A.(PH); polarimetry, optical testing, optical design Duthie, J.G. (PH); nonlinear optics, optical processing

Fork, R. L. (ECE); ultrafast phenomena, laser fibers Gilbert, J. A. (MAE); experimental stress analysis, fiber sensors, panoramic imaging Gregory, D. A. (PH); optical processing Hillman, L. W.(PH); optics laser dynamics Kowel, S. T. (ECE); polymers and liquid crystals for interconnects and displays Kulick, J. H. (ECE); computer-generated holography, medical image processing Lindquist, R. G. (ECE); nonlinear materials, holographic displays Madarasz, F. L. (CAO); E-O materials/devices Nordin, G. P. (ECE); holographic memories, diffractive displays Poularikas, A. D. (ECE); statistical optics Shen, D. (ECE); detectors, microfabrication Sung, C. C. (PH); optics, solid state physics Vikram, C.S. (CAO); holography, metrology.

Five faculty members are fellows of OSA, SPIE, or APS. More than 15 faculty members from $\mathrm{UAH}, \mathrm{UA}, \mathrm{UAB}, \mathrm{AAMU}$, and corporate and federal scientists and engineers make up the adjunct faculty. 


\section{THE OSE PROGRAM}

The program consists of coursework, a preliminary examination, a qualifying examination, and a defense of dissertation. Because students will come into this program with strong but diverse undergraduate and graduate training, the multidisciplinary curriculum has been structured on a common basis for all entering students, but compensates for individual differences to provide depth in specific areas. A total of 48 semester hours of graduate work, and a minimum of 24 semester hours of dissertation research are required. The student must complete three study phases, punctuated by three program examinations.

Phase I (the core phase) will consist of 27 semester hours of coursework. To complete this phase and become eligible for continuation in a specialty area, the student must pass the Preliminary Examination. (Only two attempts will be permitted.) After successful completion of this phase, the student should have acquired the common optics background that the program faculty believe is necessary. Full-time students will normally select a dissertation advisor during their first year and may begin dissertation research. Once an advisor has been chosen and the Preliminary Examination passed, a graduate committee will be appointed and a Program of Study completed. The second and third phases of the student's curriculum are planned by the student's graduate committee.

Phase II of the program consists of coursework in preparation for entering Phase III which consists of dissertation research. In this second phase, the student must complete the basic 48 hours of graduate coursework, including the 27 hours taken in preparation for the Preliminary Examination. The remaining courses are to be decided jointly by the student, the advisor, and the student's graduate committee. Of the 48 hours, at least 36 should be in designated optics courses, and the remainder will be selected in such a way as to prepare the student for research in his chosen optics specialty.

The second phase is completed when the student has completed most of the formal coursework as prescribed in the Program of Study and has passed the Qualifying Examination, which is prepared and administered by the student's graduate committee. It contains both written and oral parts. The written part includes a proposal for dissertation research prepared by the student and distributed to the graduate committee. The proposal must demonstrate that the student is intimately familiar with the proposed research area, that published research related to the proposal has been reviewed, and that the student has a clear understanding of how to proceed and can set realistic goals. The graduate committee may also administer a written examination using questions based on the coursework in the student's Program of Study. If the student fails the Qualifying Examination, a second attempt will be scheduled. Students who fail in two attempts will be dropped from the program.

Because the Ph.D. is a research degree, its recipients must have demonstrated the ability to perform independently and effectively report on their original research, all students are expected to acquire a majority of their advanced knowledge through research training and related activities. This includes laboratory research, group seminars, directed readings and special research topics courses. These activities of Phase III will be directly supervised by the 
student's advisor. A minimum of 24 semester hours of dissertation research is required. The Final Examination will consist of a public, oral presentation and defense of the dissertation.

\subsection{Core curriculum}

Students must hold or acquire a core of basic knowledge, which includes the contents of nine core courses described below. Because of the anticipated diversity of backgrounds of entering students, a rigid list of required prerequisite courses is inappropriate. Instead, the optics faculty will steer students into courses on the basis of background evaluation given them upon admission. Students will be given a recommended reading list for study prior to their arrival at UAH. The purpose of these steps is to ensure that entering students have achieved a minimum level of experience before starting Phase I of the program. While faculty, and in particular the advisor, will offer guidance, a passing grade in the Preliminary Examination is the sole OSE Program requirement for completion of the core. Of course, all requirements of the School of Graduate Studies must be met to remain in good standing.

The core is divided into nine topical areas grouped into three major areas. Students must gain the required knowledge contained in the core courses, but they can use experience gained elsewhere to prepare for the Preliminary Examination. The nine core courses grouped in three major areas are:

Optical Systems And Engineering

1. Geometrical Optics

2. Physical Optics

3. Optical Testing

\section{Quantum Optics}

4. Quantum Mechanics for Optics and Solid State

5. Optical Properties of Matter

6. Lasers

Optical Signals

7. Linear Systems

8. Fourier Optics

9. Random Signals and Noise

\subsection{Advanced program}

Each student will be examined in the three broad areas identified above. Many students who are in possession of an M.S. or M.S.E. degree in a relevant science or engineering discipline will be advised to take the examination upon entry.

There will be two types of full-time students, designated as graduate fellows or graduate assistants. Graduate fellows have no other responsibilities than the pursuit of their graduate studies. They may be persons on paid leave from their regular employer or they may hold one of many varieties of graduate fellowships that support full-time graduate study with no other major requirements. Graduate fellows should be able to complete the core requirements and take the Preliminary Examination after one full year of study. Indeed, this attractive feature of 
the program would allow corporations to send employees for a one-year intensive study program at UAH with the goal of completing Phase I of the program. The other full-time students, graduate assistants, are the traditional graduate students who have teaching or research commitments for which they receive payment but which demand half their work time. Such students entering with a baccalaureate degree would not normally be prepared to take the Preliminary Examination until they have completed two years of graduate study.

Although the core courses are not required, they are all covered in the Preliminary examination. All are offered every academic year (some are offered more often) to ensure that every student can prepare for the exam during the first year of study, ensuring that we can quickly determine any weaknesses.

A variety of optics-related courses are available, most offered under ECE, MAE, or PH designations. Among the topics are electromagnetic theory, statistical communication theory, optical systems design, optical communications, uniform geometrical theory of diffraction, fiber optics, nonlinear optical devices, statistical optics, numerical methods in electromagnetics, coherent optical systems and holography, electro-optical engineering, optical transforms and pattern recognition, image processing, quantum theory of solids, and optical techniques in fluid mechanics. Many other courses in the mathematical, physical and biological sciences as well as engineering are available.

More information on courses and programmatic details are available over the World Wide Web at http://info.uah.edu/Catalog/Departments/OptSciEng/goptscieng.html. The Program can be reached on the Internet at ose@ebs330.eb.uah.edu.

\section{CURRENT STATUS}

The program had 13 students in June, 1995, and expects to have 15 in the Fall. Seven are foreign nationals, three are women, and one is an African American. The overall quality is not as high as we ultimately expect to attain, but most students are making excellent progress. We have been gratified to note that students applying to, and being accepted to, the very best programs, are applying and seriously considering the OSE program at UAH.

Of seven students who took the preliminary exam the first time it was offered (September, 1994), five passed. One of those students subsequently completed all degree requirements and was awarded the Ph.D. degree in May, 1995, after submitting a dissertation in the area of dynamical optical inspection. He was offered, and accepted, a position in applied optics with a major high technology corporation.

Because of the need for interunit coordination on issues such as advising, teaching assignments, graduate teaching assistantships for OSE students, and course content, these matters must have wide discussion. The program cannot operate without strong support from, and cooperation among, the various academic and research units. As far as these architectural issues, we believe that the program is developing well. The Program Committee has operated for three years with harmony and enthusiasm. The committee has welcomed new faculty from the academic departments and from the CAO into the program. Teaching assignments are discussed during yearly meetings of the entire OSE faculty, and 
cooperation among the departmental chairs and the CAO director has been excellent. Many courses are being crosslisted among participating departments. Both the ECE and Physics Departments have provided appropriate laboratory teaching assignments for OSE students. Faculty in all departments have felt free to encourage students to pursue the OSE degree when the program seemed most appropriate for the student. One student is supported within the $\mathrm{CAO}$; all other full-time students are supported by teaching or research assistantships.

Our experience indicates that a program which puts forth optics as a distinct discipline is viable and consistent with the increasing relevance of optics to a broad range of applications in microelectronics, chemistry, inspection, materials science, information processing and communications. A multidisciplinary program can offer great flexibility and breadth, but must have the active support of the participating units. This support depends upon a clear sense that the institution, and its components, will be able to attract more research and better students with a unique, modern program, than would be possible with only its traditional program. At UAH, optics has been a significant thrust area for instruction, research, and development for a decade. The doctoral program is the planned culmination of investment in faculty, facilities, and programs.

\section{SUMMARY}

We have briefly described the initial experiences with our Ph.D. Program in Optical Science and Engineering. We have assembled an excellent faculty which spans modern optoelectronics well, and we are working to add faculty in several areas, especially integrated optics and microfabrication techniques. Based on the performance of our students, we will revise the program as needed. We intend to work to develop the cooperation with AAMU, UAB, and UA, especially in areas such as optical communication systems and biological and medical applications of optics.

$\mathrm{UAH}$ is fortunate to be located in an important center of technology development, with corporate facilities (e.g., SCI, Intergraph, Boeing, Lockheed, BDM, SAIC, Rockwell International, ADRAN, Dynetics, Summa, Wyle, Coleman Research), as well as major federal installations (NASA Marshall Space Flight Center, Army Missile Command, and the Army Space and Strategic Defense Command. These organizations employ nearly 20,000 scientists and engineers, many of whom are pursuing advanced degrees at UAH, permitting us to offer almost all of the courses relevant to the OSE program every year. Corporate and government support for student tuition and research programs makes possible this ambitious program of graduate education.

As the OSE Program becomes better known in Huntsville and across the Nation, we expect an increase in the quality and quantity of students in the program. We also expect that our traditional programs in engineering and science will also benefit through enhanced faculty and student recruitment. 